\title{
Changes in kinematic parameters during walking in adults with low back pain subjected to Vojta therapy. A pilot study
}

\author{
DOI: https://doi.org/10.5114/pq.2019.84273
}

\author{
Patrycja Łozińska1', Dorota Wójtowicz'1, Przemysław Wdowiak², Alicja Dziuba-Słonina1 \\ ${ }^{1}$ Department of Physiotherapy in Motor Organ Dysfunctions, Functional Diagnostics Unit, University School \\ of Physical Education in Wroclaw, Wroclaw, Poland \\ ${ }^{2}$ WDO-MED Private Centre of Neurological Rehabilitation, Wroclaw, Poland
}

\begin{abstract}
Introduction. The aim of the study was to evaluate changes in selected basic and derivative kinematic parameters of gait in adult patients with low back pain subjected to Vojta therapy.

Methods. The study included 17 patients with low back pain subjected to Vojta therapy. Gait parameters were assessed with G-SENSOR, the wireless inertial measurement unit system for gait analysis. The device was placed on the body of the patient in the lumbar region at the level of $L 4-L 5$, and enabled to obtain accurate and objective information on kinematic gait parameters. Results. Out of the 17 spatial and temporal parameters analysed, 3 changed significantly. The cadence decreased, and the duration of the right and left limb walk cycles increased.

Conclusions. Rehabilitation with Vojta therapy may improve spatial and temporal gait parameters in adults with low back pain. Key words: gait, three-dimensional analysis, low back pain
\end{abstract}

\section{Introduction}

Low back pain (LBP) is one of the most common problems of the musculoskeletal system. It is estimated that it can affect even $80 \%$ of the general population. Diseases of the spine are currently a social problem globally. They are the most frequently reported problems in all populations studied, regardless of the country. Symptoms of low back disorders accompany various diseases. As a result, physical, social, and professional functioning is reduced, which in turn impacts on the emotional status of those affected [1].

Diseases of the musculoskeletal system were ranked third among health problems of middle-aged people. They occur in more than half of the population over 50 years of age [2]. In approximately $2-7 \%$ of people, acute LBP evolves into chronic pain in the later stages of the disease. Chronic LBP which lasts longer than 3 months has been observed in 15$45 \%$ of the population. This condition is also one of the most common reasons of disability in people aged 45-65 years. A review conducted between 1992 and 2006 showed that the frequency of chronic LBP had doubled and was higher in women. Although the incidence of LBP is low in children $(1-6 \%)$, recent studies have reported an increase in an early onset of this condition in teenagers [3].

In the treatment of chronic LBP, conservative methods such as exercise, rehabilitation, and pharmacotherapy are used. Those techniques increase mobilization and reduce pain, as well as improve functional status and mental state. Exercises are among the main methods of treatment of chronic LBP. It has been shown that they reduce the duration and frequency of back pain $[4,5]$. Owing to severe pain, some types of therapy may be limited or unavailable. Also, some patients tolerate pain well, while others may react sharply to the slightest intervention of the therapist. The therapy for patients with LBP should be based on painless methods, so that patients could improve their condition without negative experiences, e.g. pain. A multitude of potential causes for back pain lead to the development of further research on various forms of its prevention and treatment. It is still difficult to determine which structures are the most important for the reduction or complete elimination of back pain [6].

One of the means appropriate for patients with LBP is a kinesiology concept developed by Prof. Vaclav Vojta. Vojta therapy is based on the facilitation of nerve connections in the central nervous system, which includes spatial and temporal summation. Owing to the spatial and temporal summation, relevant signals reach the brain, and next, as a result of stimulation, they activate a program of reflex rolling and creeping which exists since birth. It is worth highlighting that this method does not focus on specific motor functions, but activates muscle groups necessary to perform a given motor function - part of the global pattern of reflexive locomotion [7].

Physiological gait is characterized by certain variability, particularly in the scope of muscle activity; therefore, 'normal gait pattern' and 'normal variability range' are discussed as its measurable characteristics. Different functions of the motor system can lead to a change in the gait pattern. Those disorders may not always be seen while observing the patient and thus it may be necessary to use specialist devices to detect them. One of the devices widely used by biomechanics specialists, physiotherapists, kinesiologists, or doctors is a three-dimensional gait analysis system. A comparison of gait analysis of patients with normal values is the basis for important decisions regarding treatment and allows to assess the effects of rehabilitation [8]. A gait pattern develops as a result of complex interactions of neuromuscular and skeletal components of the human motor system. Pathological gait

Correspondence address: Alicja Dziuba-Słonina, University School of Physical Education, Department of Physiotherapy in Motor Organ Dysfunctions, al. Paderewskiego 35, 51-612 Wrocław, Poland, e-mail: alicja.dziuba@awf.wroc.pl 
follows a dysfunction of an individual component of this system or many dysfunctions affecting all its components. It can also be caused by pain perceived by the patient. In such a case, a person potentially able to walk properly may prefer an altered form of movement, different from the ideal pattern [9].

Gait is characterized by the coordinated work of many skeletal muscles. Because of the high degree of flexibility of the musculoskeletal system, each step slightly differs from the previous one. For this reason, gait is not perfectly repeatable even in the case of walking on a flat surface. Small differences in kinematic and kinetic measurements should be regarded as a norm. However, if the left lower extremity performs a shorter stride than the right one consistently, it should be considered a symptom of asymmetric gait that may result from certain pathologies [10]. People suffering from LBP present with a disturbed, abnormal gait pattern which is characterized by a reduced stride length, a greater stride width, disturbed trunk coordination, and a slower gait rate. An additional factor that significantly affects gait velocity was noted by Hortobágyi et al. [11]. They discovered an interaction between age and gait velocity in the amplitude and timing of antagonist muscle coactivation. According to Lamoth et al. [12], one of the theories explaining the pathogenesis of abnormal gait in LBP is the adoption of an unintentional strategy. This means that the person affected by LBP modifies their pattern of muscle activity trying to reduce the perception of pain. In other words, the person adopts a protective strategy limiting spinal movements. Lamoth et al. [13] emphasize the importance of psychogenic factors such as anxiety and chronic musculoskeletal pain. Avoiding physical activity, which is associated with an increase in pain, may lead to a change in the gait pattern. It has also been suggested that people with LBP show worse motor control, reduced perception of proprioceptive sensibility, and, as a result, decreased ability to adapt their gait pattern to changing conditions and to cope with unexpected disorders. Della Volpe at al. [14] report that in patients with chronic LBP, postural stability under difficult conditions is maintained by increased anterior-posterior deflections. This change in the posture strategy may underlie dysfunctions of the peripheral proprioceptive system or the central integration of proprioceptive information.

The aim of the study was to evaluate changes in selected kinematic gait parameters in adult patients with LBP subjected to Vojta therapy.

The use of non-steroidal anti-inflammatory drugs in the treatment of chronic pain in the lumbar region provides shortterm benefits [15]. Additionally, many patients present with side effects of such medication [16]. Severe pain can make some therapy options limited or unavailable. Treatment offered to patients with low back disorders should be based on painless modalities so that the patient could improve their condition without experiencing negative sensations, including pain. The multiplicity of potential causes for chronic LBP leads to the conduct of further research and the development of various forms of its prevention and treatment [6]. Vojta therapy can painlessly reduce symptoms of LBP by restoring correct movement patterns; as a result, it can improve gait of people affected by LBP.

\section{Subjects and methods}

\section{Participants}

The study included 17 patients (16 women and 1 man) with spinal LBP subjected to Vojta therapy. Their mean age was $49.1 \pm 15.6$ years, their body mass $73.0 \pm 20.5 \mathrm{~kg}$, and body height $1.65 \pm 0.05 \mathrm{~m}$.
The study was conducted in the WDO-MED Private Centre of Neurological Rehabilitation in Wroclaw, Poland. The inclusion criteria were as follows: the presence of spinal pain in the sacral or in the sacral and lumbar region, lack of severe orthopaedic or neurological diseases resulting in gait disorders, logical visual and verbal contact with the patient, independent walk without assistance, and informed consent for participation in the study.

Almost $71 \%$ of the group analysed consisted of participants aged 40-69 years. The study group comprised 2 people up to 30 years of age and 2 subjects over 70 years of age. The mean age of the participants was 49 years.

\section{Study design}

Parameters of the gait pattern were assessed with a system for motion analysis (BTS G-SENSOR): a portable device using a tri-axial accelerometer, tri-axial sensors of the magnetic field, and tri-axial gyroscopes. The device was placed on the body of the patient in the lumbar region at the level of L4-L5, and enabled to obtain accurate and objective information on the spatial and temporal gait parameters. In the study, the advanced WALK protocol was applied, which is used to assess gait pathology in the scope of kinematic parameters. The BTS G-SENSOR is a reliable device for measuring all spatial and temporal gait parameters [17]. Each patient was examined twice with the BTS G-SENSOR: (1) directly before the Vojta therapy and (2) after a 50-minute treatment. During the examination, each subject had to walk 5 meters along a corridor, turn back, and return to the starting point. No restrictions were imposed on the duration of the walk.

The following parameters were analysed:

- analysis duration, $\mathrm{t}(\mathrm{s})$;

- cadence, f (steps/min);

- velocity, v (m/s);

- stride length for the right and left leg, SL (m);

- stride length for the right and left leg calculated as percentage of body height, SL (\%);

- walking cycle duration for the right and left leg, $t_{\mathrm{SL}}(\mathrm{s})$;

- support phase duration for the right and left leg calculated as percentage of cycle time, ST (\% cycle time);

- swing phase duration for the right and left leg calculated as percentage of cycle time, SP (\% cycle time);

- double support phase duration for the right and left leg calculated as percentage of cycle time, DSP (\% cycle time);

- single support phase duration for the right and left leg calculated as percentage of cycle time, SS (\% cycle time).

The examination was divided into 3 stages, depending on the 3 series of obtained measurement results:

- series I: 17 patients were examined directly before and after the 50-minute Vojta therapy;

- series II: 8 patients out of those examined in series I were examined directly before and after the 50-minute Vojta therapy; the measurements took place after 5 cycles of the therapy were completed;

- series III: 5 patients out of those examined in series II were examined directly before and after the 50-minute Vojta therapy; the measurements took place after 10 cycles of the therapy were completed.

The participants were subjected solely to Vojta therapy because of the presence of severe pain. The study did not include a control group receiving conservative treatment applied in this type of disorders because of severe pain perceived by the patients and the lack of possibility of therapy standardization. 
The measurements taken in each series were analysed in terms of spatial and temporal parameters characteristic of gait.

\section{Statistical analysis}

The statistical analysis was carried out with the Statistica software v. 13 (StatSoft, Tulsa, USA). The Shapiro-Wilk test was used to analyse the distribution of the data. To compare the kinematic measurements taken before and after treatment, as well as between the series, several tests were applied. The Student's $t$-test for independent variables and the Wilcoxon signed-rank test, which is a non-parametric alternative for the Student's $t$-test when the assumptions for its implementation are not valid, were used to verify the hypothesis about the size of the differences between the obtained results of spatial and temporal parameters. The Cohen's $d$-factor served to estimate the magnitude of the effect. Statistical hypotheses were verified at the significance level of $p=0.05$.

\section{Ethical approval}

The research related to human use has been complied with all the relevant national regulations and institutional policies, has followed the tenets of the Declaration of Helsinki, and has been approved by the Senate Research Ethics Committee at the University School of Physical Education in Wroclaw.

\section{Informed consent}

Informed consent has been obtained from all individuals included in this study.

\section{Results}

Out of the 17 spatial and temporal parameters analysed in series I, 3 changed significantly: cadence and the duration of the gait cycle for both the left and right lower extremity.

In the study group, the median cadence dropped from 109 to $104 \mathrm{steps} / \mathrm{min}$ as a result of the therapy, while the median length of the stride and gait velocity increased (Figure 1).

Owing to the elongation of the stride length as a result of the Vojta therapy, the duration of the gait cycle increased significantly for both the left and right lower extremity. Also, the mean gait velocity increased, with a simultaneous increase in the stride length, and this contributed to the increase in the ratio of the stride length to the patient's height by nearly $3 \%$. As for the effect size, estimated with Cohen's $d$-factor, the value of the indicator was $d=0.39$ for cadence (medium effect size), $d=0.22$ for duration of the walking cycle for the left lower limb (small effect size), and $d=0.26$ for duration of the walking cycle for the right lower limb (small effect size).

In the next stage of the analysis, spatial and temporal parameters obtained by patients between series I and series II of tests were compared. Because of the small number of the sample studied (only 8 patients participated in the test), the analysis was based solely on the comparison of relevant statistical measures.

The analysis of the results of series II showed that rehabilitation with Vojta treatment increased gait velocity (Table 1). Taking into account the results of series II, the comparison of gait velocity between the measurements before $(1.27 \mathrm{~m} / \mathrm{s})$ and after Vojta therapy $(1.38 \mathrm{~m} / \mathrm{s})$ presented an increase by $8.9 \%$, while the comparison of the measurements before series I $(1.02 \mathrm{~m} / \mathrm{s})$ and before series II $(1.27 \mathrm{~m} / \mathrm{s})$ revealed an increase by $36.0 \%$. Along with the increased velocity, an
Table 1. Descriptive statistics of the analysed gait parameters: series II

\begin{tabular}{|c|c|c|c|c|}
\hline \multicolumn{2}{|l|}{ Parameter } & $\bar{x}$ & $M$ & $S D$ \\
\hline \multirow{3}{*}{ t (s) } & $1 a$ & 28.7 & 25.9 & 11.0 \\
\hline & $2 a$ & 20.9 & 20.0 & 4.4 \\
\hline & $2 b$ & 20.9 & 21.1 & 6.3 \\
\hline \multirow{3}{*}{ f (steps/min) } & $1 a$ & 107.0 & 109.0 & 15.1 \\
\hline & $2 a$ & 108.1 & 110.6 & 13.8 \\
\hline & $2 b$ & 110.0 & 107.3 & 21.8 \\
\hline \multirow{3}{*}{$v(\mathrm{~m} / \mathrm{s})$} & $1 a$ & 1.02 & 1.08 & 0.24 \\
\hline & $2 a$ & 1.27 & 1.15 & 0.55 \\
\hline & $2 b$ & 1.38 & 1.15 & 0.79 \\
\hline \multirow{3}{*}{$\mathrm{t}_{\mathrm{SL}} \mathrm{L}(\mathrm{s})$} & $1 a$ & 1.23 & 1.16 & 0.24 \\
\hline & $2 a$ & 1.13 & 1.09 & 0.16 \\
\hline & $2 b$ & 1.13 & 1.12 & 0.22 \\
\hline \multirow{3}{*}{$t_{S L} R(s)$} & $1 a$ & 1.22 & 1.15 & 0.24 \\
\hline & $2 a$ & 1.12 & 1.09 & 0.16 \\
\hline & $2 b$ & 1.12 & 1.12 & 0.21 \\
\hline \multirow{3}{*}{ SL L (\%) } & $1 a$ & 49.8 & 50.4 & 1.76 \\
\hline & $2 a$ & 51.1 & 50.3 & 3.40 \\
\hline & $2 b$ & 50.3 & 49.3 & 3.63 \\
\hline \multirow{3}{*}{ SL R (\%) } & $1 a$ & 50.2 & 49.6 & 1.76 \\
\hline & $2 a$ & 48.9 & 49.7 & 3.40 \\
\hline & $2 b$ & 49.8 & 50.7 & 3.63 \\
\hline
\end{tabular}

$1 \mathrm{a}$ - parameters before Vojta therapy in series I, $2 \mathrm{a}$ - parameters before Vojta therapy in series II, $2 \mathrm{~b}$ - parameters after Vojta therapy in series II, $\mathrm{t}$ - analysis duration, $\mathrm{f}$ - cadence, $\mathrm{v}$ - velocity, $t_{S L}$ - duration of gait cycle, SL (\%) - stride length as percentage of body height, $\mathrm{L}$ - left leg, $\mathrm{R}$ - right leg, $\bar{x}$ - mean, $M$ - median, $S D$ - standard deviation

increased stride length was observed: by $6 \mathrm{~cm}$ in comparison with the mean stride length before series II and by 22 $\mathrm{cm}$ in comparison with the mean stride length before series I. Cadence, defined as the number of steps per minute, increased as well: from $100 \mathrm{steps} / \mathrm{min}$ before series I to 108 steps/min before series II and to 110 steps/min directly after series II of the therapy.

The duration of gait cycle for the right and left lower extremity after Vojta therapy in series II of the study remained on the level obtained before the therapy and decreased by $0.10 \mathrm{~s}$ in comparison with the duration of gait cycle observed before series I for both extremities. The difference in the duration of gait cycle between the left and right lower extremity remained on the same level and amounted approximately $1 \%$ (i.e. $0.01 \mathrm{~s}$ ); the cycle was longer for the left lower limb than for the right one.

In the last stage of the research work, a comparison was performed of kinematic parameters in relation to series III (directly before and after Vojta therapy) and the results obtained before the therapy in series I of the study. Only 5 patients participated in series III, thus also in this case, the analysis of spatial and temporal parameters consisted in a comparison of simple statistical measures. 

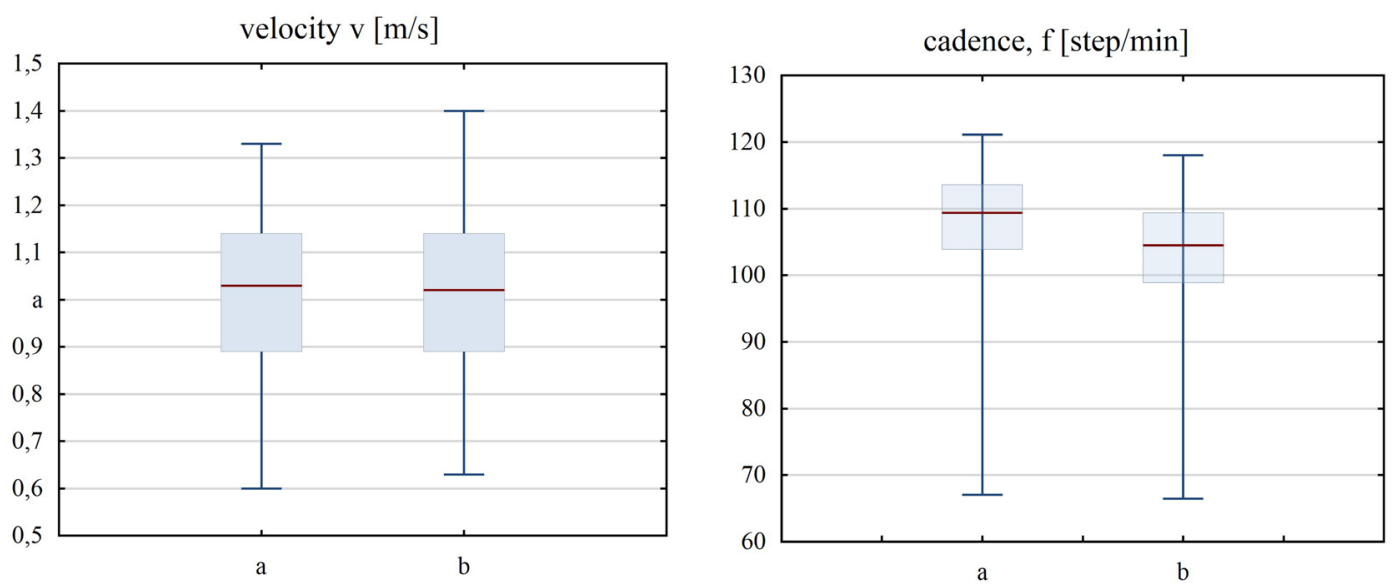

walking cycle duration for right leg, $\mathrm{t}_{\mathrm{SL}}[\mathrm{s}]$

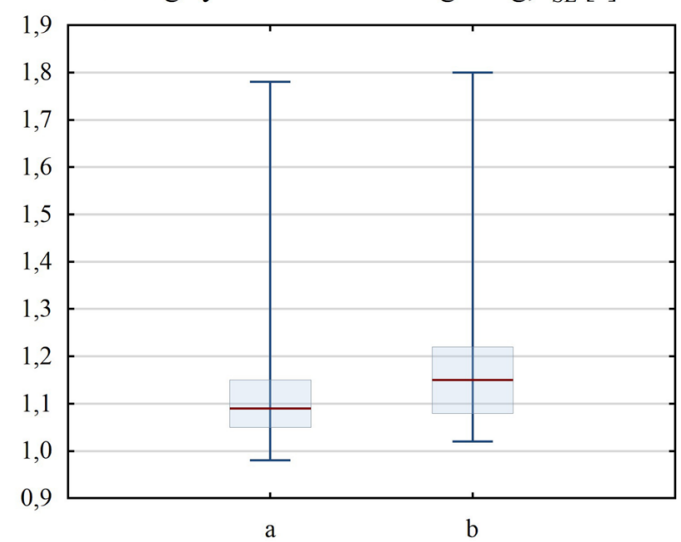

walking cycle duration for left leg, $\mathrm{t}_{\mathrm{SL}}$ [s]

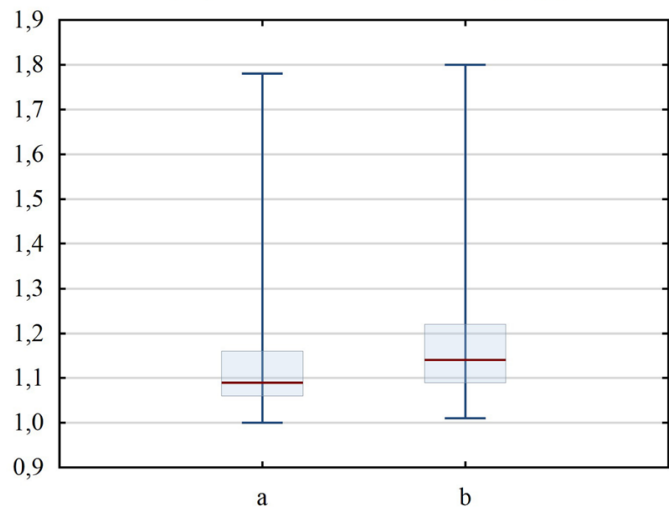

stride length for right leg percentage of body height, SL[\%]

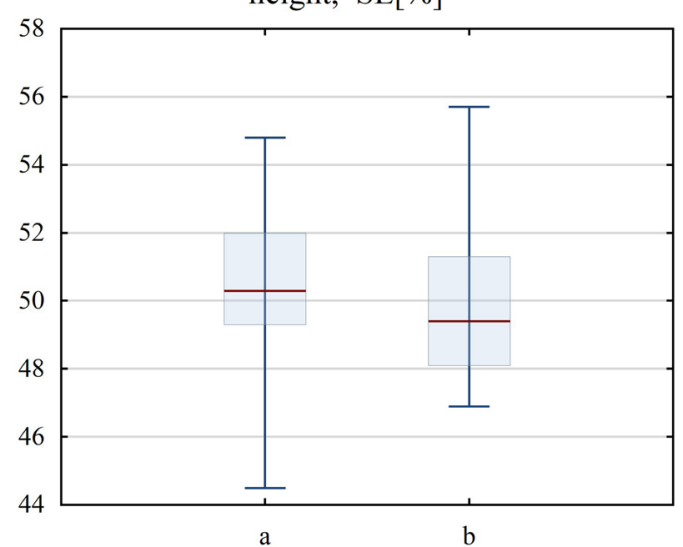

stride length for left leg in percentage of body height, SL[\%]

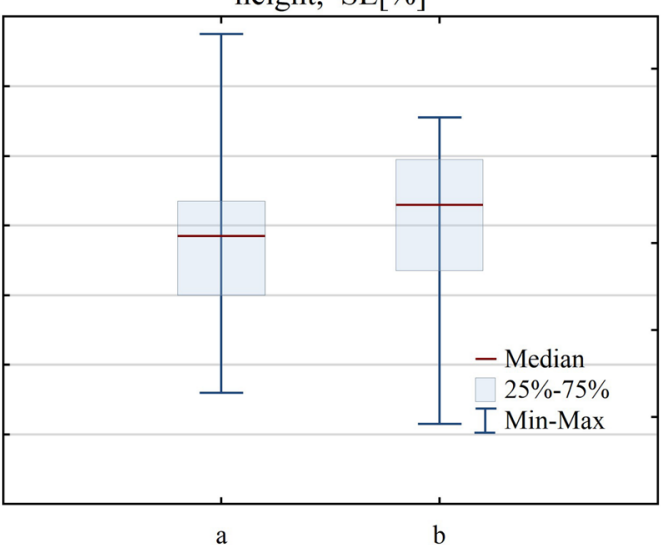

stride length SL [m]

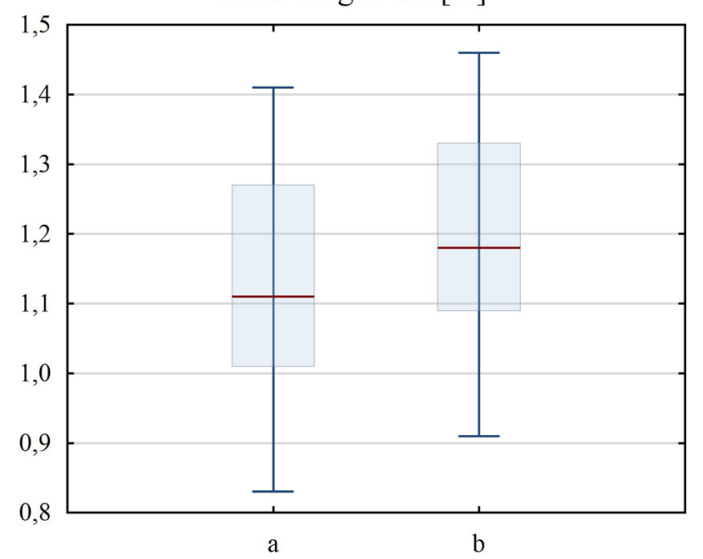

Figure 1. Series I measurements (median): frame plots of distributions of spatial and temporal parameters before (a) and after (b) the Vojta therapy 
Table 2. Descriptive statistics of the analysed gait parameters: series III

\begin{tabular}{|c|c|c|c|c|}
\hline \multicolumn{2}{|l|}{ Parameter } & $\bar{x}$ & M & SD \\
\hline \multirow{3}{*}{$t(s)$} & $1 a$ & 26.6 & 20.4 & 12.9 \\
\hline & $3 a$ & 22.8 & 19.8 & 7.82 \\
\hline & $3 b$ & 24.2 & 20.3 & 9.35 \\
\hline \multirow{3}{*}{ f (steps/min) } & $1 a$ & 107.0 & 109.0 & 19.22 \\
\hline & $3 a$ & 96.1 & 109.1 & 22.18 \\
\hline & $3 b$ & 98.5 & 109.7 & 18.43 \\
\hline \multirow{3}{*}{$\mathrm{v}(\mathrm{m} / \mathrm{s})$} & $1 a$ & 1.04 & 1.13 & 0.28 \\
\hline & $3 a$ & 1.02 & 1.16 & 0.36 \\
\hline & $3 b$ & 1.05 & 1.26 & 0.33 \\
\hline \multirow{3}{*}{$\mathrm{t}_{\mathrm{SL}} \mathrm{L}(\mathrm{s})$} & $1 a$ & 1.24 & 1.14 & 0.31 \\
\hline & $3 a$ & 1.32 & 1.09 & 0.34 \\
\hline & $3 b$ & 1.26 & 1.09 & 0.26 \\
\hline \multirow{3}{*}{$t_{S L} R(s)$} & $1 a$ & 1.24 & 1.15 & 0.31 \\
\hline & $3 a$ & 1.32 & 1.10 & 0.34 \\
\hline & $3 b$ & 1.26 & 1.09 & 0.26 \\
\hline \multirow{3}{*}{ SL L (\%) } & $1 a$ & 49.2 & 49.2 & 1.89 \\
\hline & $3 a$ & 50.2 & 49.0 & 3.33 \\
\hline & $3 b$ & 51.1 & 50.8 & 3.69 \\
\hline \multirow{3}{*}{ SL R (\%) } & $1 a$ & 50.8 & 50.8 & 1.89 \\
\hline & $3 a$ & 49.8 & 51.0 & 3.33 \\
\hline & $3 b$ & 48.9 & 49.2 & 3.69 \\
\hline
\end{tabular}

$1 \mathrm{a}$ - parameters before Vojta therapy in series $\mathrm{I}, 3 \mathrm{a}$ - parameters before Vojta therapy in series III, $3 \mathrm{~b}$ - parameters after Vojta therapy in series III, $\mathrm{t}$ - analysis duration, $\mathrm{f}$ - cadence, $\mathrm{v}$ - velocity, $t_{\mathrm{SL}}$ - duration of gait cycle, $\mathrm{SL}(\%)$ - stride length as percentage of body height, $\mathrm{L}-$ left leg, $\mathrm{R}$ - right leg, $\bar{x}-$ mean, $M$ - median, $S D$ - standard deviation

On the basis of the analysis of the results from series III of the study (Table 2), trends indicating a positive influence of rehabilitation with Vojta therapy on kinematic parameters of gait in patients experiencing pain in the spinal area can be observed. The mean parameters of the stride length increased by $1 \mathrm{~cm}$ in comparison with the measurements before the therapy in series III and by $2 \mathrm{~cm}$ in comparison with the measurements before the therapy in series I of the study. Similarly, velocity and cadence increased in comparison with the results before the therapy, along with a decrease in cadence in comparison with the mean value obtained by patients before the therapy in series I of the study. The mean duration of gait after the therapy was lower in comparison with the values obtained in series III, but higher when compared with the values before rehabilitation in series I.

\section{Discussion}

Vojta therapy is one of the few methods that affect the automatic control of body posture. Vojta discovered that when the patient lay down in a certain position and the therapist worked on a precisely defined point located on a muscle, bone, or even in the intercostal space of the patient, the so- called innate patterns of movement (automatic regulation of body posture) could be activated. Everyone has coded patterns in the central nervous system. Therefore, activities such as walking, sitting, and standing up can be performed automatically: in each case, an innate pattern of movement is applied. Vojta therapy is rarely used in adults in comparison with children because of great brain plasticity in the latter. The impact of the therapy can be seen already after a single several-second stimulation.

Jung at al. [18] compared the impact of Vojta therapy with the neuro-developmental treatment (NDT) according to the Bobath approach. The more significant effect achieved after applying Vojta therapy than with NDT can be explained by more intensive muscle activation as a result of precisely directed motor reactions to the triggered reflexes. However, more and more often the studies include adults. Gajewska et al. [19], among other researchers, evaluated muscle reactions after stimulation with Vojta therapy. They considered possible routes of spinal transmission responsible for the phenomenon of muscle activation in the upper and lower limbs. The authors claim that long neurons of propriospinal tracks are among the possible pathways responsible for the major lumbar neuronal transmission engaged in the mechanism of Vojta therapy. Hok et al. [20] studied the impact of Vojta therapy on the activity of the central nervous system. They revealed that the locomotion reflex triggered by Vojta therapy was associated with specific changes in the cortical and subcortical activity of the brain. In another study performed by Hok et al. [21], the plasticity of the sensorimotor system under stimulation by Vojta therapy was explored. The results indicate that Vojta therapy causes specific and permanent changes in brain activity, mainly at the subcortical level. Lim and Kim [22] proved that Vojta therapy increased the gait rate during the initial phase of the treatment. Also, gait velocity and duration of a single mid-stance increased in comparison with baseline. The motion range in the sagittal plane increased in the hip and knee joints but decreased slightly in the ankle joints.

Syczewska [23] reported that the mobility of the L4-S2 segment in the sagittal plane while walking was strictly associated with the mobility of the hip joints. The largest movement amplitudes (of approximately $2^{\circ}$ ) occur in the Th10-L4 segments of the spine. On top of this, the movement of the spine segments and the shoulder girdle in relation to the pelvic girdle depends on gait velocity. The present study allows to assume that in patients with LBP treated with Vojta therapy, the mobility of the hip joints, which is associated with lumbar-sacral section, increases. As a result, the mean gait velocity increases with the elongation of the stride length. Pietraszewski et al. [24] noted the relationship between high, preferred, and low gait velocity. An increase in gait velocity was associated with a change in the angular range of motion in the hip, knee, and ankle joints in the sagittal plane. Similar correlations were observed in the pelvis, as well as in the hip, knee, and ankle joints in the frontal and transverse plane. As a result of an increase in gait velocity, the range of motion also increases. Our findings can be linked to conclusions made by Lamoth et al. [12], who claim that during physiological gait in people with LBP, the synchronization of the trunk and rotation of the pelvis, as well as the activity of erector spinae change systematically with walking velocity, while trunk-pelvis coordination is often reduced or absent. Lamoth et al. [13] suggest that the lower rate of walking is associated with the presence of pain and fear of provoking pain, which may be a reason for limiting spinal movements. In both the acute and chronic stage of LBP, an increased 
activity of the lower spine during the swing phase is demonstrated, while muscles of this area usually present low activity. Taking into account that trunk coordination is related to gait stability, it should be noted that people with LBP may experience difficulties with coping with perturbations while walking. Steele et al. [25] concluded similarly on spine erector and found that gait variability might be a consequence of deconcentration of spine erector or disability accompanying chronic LBP [25].

Vojta therapy is still not very popular in adult patients. The literature review, however, reveals an increasing interest in the impact of this therapy among adults. Because of severe pain in chronic LBP, it is worth considering this painless therapy option, which, in comparison with pharmacotherapy necessary for the normal functioning of patients affected by chronic LBP, is not associated with the risk of any side effects. The present study may be a constructive introduction to further research on the assessment of Vojta therapy effect in adults.

\section{Limitations}

Because of the low interest in Vojta therapy among adult patients, the method is currently rarely employed in this setting. For this reason, the treated group was relatively small and thus the achieved results are less reliable.

\section{Conclusions}

Rehabilitation with Vojta therapy may improve spatial and temporal parameters in adults with LBP. In the presented study, 3 spatio-temporal parameters have changed statistically significantly: cadence (at a moderate level), as well as the gait cycle duration for the left and right lower limb (at a small level).

\section{Disclosure statement}

No author has any financial interest or received any financial benefit from this research.

\section{Conflict of interest}

The authors state no conflict of interest.

\section{References}

1. Manciopi PA, Rinaldi NM, Moraes R. Prehension combined with gait in individuals with chronic low back pain. Motor Control. 2017;21(1):90-111; doi: 10.1123/mc.20140044.

2. Kokosz M, Saulicz E. Porównanie skuteczności leczenia szpitalnego i ambulatoryjnego u chorych z dolegliwościami bólowymi dolnego odcinka kręgosłupa. Fizjoterapia. 1996;4(1-2):71-75.

3. Alleva J, Hudgins T, Belous J, Origenes AK. Chronic low back pain. Dis Mon. 2016;62(9):330-333; doi: 10.1016/ j.disamonth.2016.05.012.

4. Odinets T, Briskin Y. Impact of personality-oriented programs of physical rehabilitation on the heart rate variability in women with post-mastectomy syndrome. Physiotherapy. 2016;24(2):4-8; doi: 10.1515/physio-20160007.

5. Şahin N, Karahan AY, Albayrak I. Effectiveness of physical therapy and exercise on pain and functional status in patients with chronic low back pain: a randomizedcontrolled trial. Turk J Phys Med Rehab. 2018;64(1):5258; doi: 10.5606/tftrd.2018.1238.
6. Maciaszek J, Skrypnik D, Ratajczak M, Stemplewski R, Osiński W, Bogdański P, et al. Two aerobic exercise programs in management of back pain among middle-aged obese women: a randomized controlled study. Hum Mov. 2016;17(2):72-79; doi: 10.1515/humo-2016-0016.

7. Dytrych G. Kontrowersje wokół metody Vojty - spojrzenie terapeuty. Neurol Dziec. 2008;17(33):59-62.

8. Leszczewska J, Czaprowski D, Pawłowska P, Oponowicz A. Inter-examiner, within-session and between-session repeatability of kinematic gait parameters among adult subjects. Hum Mov. 2012;13(4):337-343; doi: 10.2478/v10038-012-0039-9.

9. Levine D, Richards J, Whittle MW. Whittle's gait analysis. Edinburgh: Churchill Livingstone; 2012.

10. Kaczmarczyk K, Błażkiewicz M, Wit A, Wychowański M. Assessing the asymmetry of free gait in healthy young subjects. Acta Bioeng Biomech. 2017;19(3):101-106; doi: 10.5277/ABB-00770-2016-02.

11. Hortobágyi T, Solnik S, Gruber A, Rider P, Steinweg K, Helseth J, et al. Interaction between age and gait velocity in the amplitude and timing of antagonist muscle coactivation. Gait Posture. 2009;29(4):558-564; doi: 10.1016/ j.gaitpost.2008.12.007.

12. Lamoth CJ, Meijer OG, Daffertshofer A, Wuisman PI, Beek PJ. Effects of chronic low back pain on trunk coordination and back muscle activity during walking: changes in motor control. Eur Spine J. 2006;15(1):23-40; doi: 10.1007/s00586-004-0825-y.

13. Lamoth CJ, Stins JF, Pont M, Kerckhoff F, Beek PJ. Effects of attention on the control of locomotion in individuals with chronic low back pain. J Neuroeng Rehabil. 2008;5:13; doi: 10.1186/1743-0003-5-13.

14. Della Volpe R, Popa T, Ginanneschi F, Spidalieri R, Mazzocchio R, Rossi A. Changes in coordination of postural control during dynamic stance in chronic low back pain patients. Gait Posture. 2006;24(3):349-355; doi: 10.1016/ j.gaitpost.2005.10.009.

15. Van Tulder MW, Scholten RJ, Koes BW, Deyo RA. Nonsteroidal anti-inflammatory drugs for low back pain: a systematic review within the framework of the Cochrane Collaboration Back Review Group. Spine. 2000; 25(19):2501-2513; doi: 10.1097/00007632-20001001000013.

16. Antman EM, Bennett JS, Daugherty A, Furberg C, Roberts $\mathrm{H}$, Taubert KA. Use of nonsteroidal antiinflammatory drugs: an update for clinicians: a scientific statement from the American Heart Association. Circulation. 2007;115(12):1634-1642; doi: 10.1161/CIRCULATIONAHA.106.181424.

17. De Ridder R, Lebleu J, Willems T, De Blaiser C, Detrembleu C, Roosen P. Concurrent validity of a commercial wireless trunk tri-axial accelerometer system for gait analysis. J Sport Rehabil. 2019;1-13; doi: 10.1123/jsr. 2018-0295.

18. Jung $M W$, Landenberger $M$, Jung $T$, Lindenthal $T$, Philippi H. Vojta therapy and neurodevelopmental treatment in children with infantile postural asymmetry: a randomised controlled trial. J Phys Ther Sci. 2017;29(2): 301-306; doi: 10.1589/jpts.29.301.

19. Gajewska E, Huber J, Kulczyk A, Lipiec J, Sobieska M. An attempt to explain the Vojta therapy mechanism of action using the surface polyelectromyography in healthy subjects: a pilot study. J Bodyw Mov Ther. 2018;22(2):287-292; doi: 10.1016/j.jbmt.2017.07.002.

20. Hok P, Hluštík P, Kutín M, Opavský J, Grambal A, Tüdös Z, et al. Changes in brain activation after therapeutic 
stimulation using Vojta therapy: controlled study. Clin Neurophysiol. 2014;125(5):e34; doi: 10.1016/j.clinph. 2013.12.067.

21. Hok P, Hluštík P, Kutín M, Opavský J, Tüdös Z, Kaňovský $P$. Plasticity of sensorimotor system induced by sustained pressure stimulation according to Vojta therapy. Neurology. 2015;84(14 Suppl):P7.197.

22. Lim H, Kim T. Effects of Vojta therapy on gait of children with spastic diplegia. J Phys Ther Sci. 2013;25(12): 1605-1608; doi: 10.1589/jpts.25.1605.

23. Syczewska M. Badanie ruchu kręgosłupa człowieka podczas chodu. Warszawa: Instytut „Pomnik-Centrum Zdrowia Dziecka"; 2010.

24. Pietraszewski B, Winiarski S, Jaroszczuk S. Three-dimensional human gait pattern - reference data for normal men. Acta Bioeng Biomech. 2012;14(3):9-16; doi: 10.5277/abb120302.

25. Steele J, Bruce-Low S, Smith D, Jessop D, Osborne N. Lumbar kinematic variability during gait in chronic low back pain and associations with pain, disability and isolated lumbar extension strength. Clin Biomech. 2014; 29(10):1131-1138; doi: 10.1016/j.clinbiomech.2014. 09.013. 